\title{
Correction to: Japan, Italy and the Road to the Tripartite Alliance
}

\section{Correction to:}

K. Ishida, Japan, Italy and the Road to the Tripartite Alliance, Security, Conflict and Cooperation in the Contemporary World, https://doi.org/10.1007/978-3-319-96223-8

The original version of the book was revised. Additional corrections from the author have been incorporated in chapters $2,3,4,6,7,8$ and backmatter.

The updated versions of these chapters can be found at https://doi.org/10.1007/978-3-319-96223-8_2, https://doi.org/10.1007/978-3-319-96223-8_3, https://doi.org/10.1007/978-3-319-96223-8_4, https://doi.org/10.1007/978-3-319-96223-8_6, https://doi.org/10.1007/978-3-319-96223-8_7, https://doi.org/10.1007/978-3-319-96223-8_8 and https://doi.org/10.1007/978-3-319-96223-8

(C) The Author(s) 2018

K. Ishida, Japan, Italy and the Road to the Tripartite Alliance, Security, Conflict and Cooperation in the Contemporary World, https://doi.org/10.1007/978-3-319-96223-8_9 